\title{
Identification of different macrophage subpopulations with distinct activities in a mouse model of oxygen-induced retinopathy
}

\author{
YANJI ZHU ${ }^{1 *}$, LING ZHANG $^{2 *}$, QING LU $^{1}$, YUSHUO GAO $^{1}$, YUJUAN CAI $^{1}$, \\ AILING SUI ${ }^{1}$, TING SU ${ }^{1}, \mathrm{XI} \mathrm{SHEN}^{1}$ and BING XIE ${ }^{1}$ \\ ${ }^{1}$ Department of Ophthalmology, Ruijin Hospital, Shanghai Jiaotong University School of Medicine, \\ Shanghai 200025, P.R. China; ${ }^{2}$ Department of Ophthalmology, \\ Johns Hopkins University School of Medicine, Baltimore, MD 21287-9277, USA
}

Received February 1, 2016; Accepted April 5, 2017

DOI: $10.3892 /$ ijmm.2017.3022

\begin{abstract}
The aim of the present study was to characterize the phenotypic shift, quantity and role changes in different subgroups of retinal macrophages in a mouse model of oxygen-induced retinopathy (OIR). The mRNA expression levels of macrophage M1 and M2 subgroup marker genes and polarization-associated genes were analyzed by RT-qPCR. The number of M1 and M2 macrophages in our mouse model of OIR was analyzed by flow cytometry at different time points during the progression of OIR. Immunofluorescence whole mount staining of the retinas of mice with OIR was performed at different time points to examine the influx of macrophages, as well as the morphological characteristics and roles of M1 and M2 macrophages. An increased number of macrophages was recruited during the progression of angiogenesis in the retinas of mice with OIR due to the proinflammatory microenvironment containing high levels of cell adhesion and leukocyte transendothelial migration molecules. RT-qPCR and flow cytometric analysis at different time points revealed a decline in the number of M1 cells from a significantly high level at post-natal day (P)13 to a relatively normal level at $\mathrm{P} 21$, as well as an increase in the number of M2 cells from P13 to P21 in the mice with OIR, implicating a shift of macrophage polarization towards the M2 subtype. Immunofluorescence staining suggested that the M1 cells interacted with endothelial tip cells at the vascular front, while M2 cells embraced the emerging vessels and bridged the neighboring vessel sprouts.
\end{abstract}

Correspondence to: Dr Bing Xie or Dr Xi Shen, Department of Ophthalmology, Ruijin Hospital, Shanghai Jiaotong University School of Medicine, 197 Ruijin Er Road, Shanghai 200025, P.R. China

E-mail: bingxie1@gmail.com

E-mail: carl_shen2005@126.com

*Contributed equally

Abbreviations: NV, neovascularization; RNV/CNV, retinal/choroidal neovascularization; Mf, macrophage; ROP, retinopathy of prematurity; Pn, post-natal day $n$

Key words: M1 macrophages, M2 macrophages, oxygen-induced retinopathy, retinal neovascularization
Thus, our data indicate that macrophages play an active role in OIR by contributing to the different steps of neovascularization. Our findings indicate that tissue macrophages may be considered as a potential target for the anti-angiogenic therapy of ocular neovascularization disease.

\section{Introduction}

Angiogenesis is an essential process for embryonic development and tissue repair, whereas abnormal angiogenesis is a fundamental characteristic in the pathophysiology of ocular diseases, such as retinopathy of prematurity (ROP), diabetic retinopathy and choroidal neovascularization (CNV), usually associated with age-related macular degeneration. Retinochoroidal neovascularization diseases can lead to blindness in developed countries (1). Among the several different therapies that are currently utilized, anti-vascular endothelial growth factor (VEGF) therapy has undoubtedly appeared to be effective (2). However, according to the SEVEN-UP study (seven-year outcome in ranibizumabtreated patients in ANCHOR, MARINA and HORIZON: a multicenter cohort), best-corrected visual acuity (BCVA) in $34 \%$ of the eyes examined declined by 15 letters or more, with an overall mean decline of 8.6 letters, at a mean of 7.3 years after entering the ANCHOR or MARINA trial (3). Similar outcomes were also observed in patients enrolled in the comparison of AMD treatment trials (CATT) study (4). Therefore, investigating additional VEGF-independent pathways that trigger abnormal angiogenesis in the eye seems critical.

Increasing evidence has suggested that macrophages play a significant role in both physiological and pathological angiogenesis (5-7). Macrophages were initially believed to be solely pro-inflammatory and destructive phagocytes until demonstrated to be able to convert to a pro-healing phenotype (8). Recently, it was reported that macrophages represent approximately $50 \%$ of the tumor mass and play vital roles in the regulation of angiogenesis and tumor progression (9). Researchers have demonstrated that cells of the monocytemacrophage lineage are characterized by diversity and plasticity, as they can shift between different activation modes driven by the local microenvironment and have divergent functions. Unique stimuli endow macrophages with distinct molecular phenotypes and effector functions (10). M1 macrophages were 
believed to produce high levels of oxidative metabolites and pro-inflammatory cytokines, and combat invading pathogens and tumor cells, while M2 macrophages promote angiogenesis and remold the matrix, orchestrating homeostasis following the inflammatory response, which was confirmed to be associated with the resolution of chronic leg ulcers (11), atherosclerotic lesions (12) and traumatic spinal cord injury (10). Yet, the roles of macrophage populations in angiogenesis remain controversial and are poorly understood (13). Some studies have found that decreased numbers of M1/M2 ratios correlate with biomaterial vascularization (14-18), while others have revealed that increased numbers of $\mathrm{M} 1 / \mathrm{M} 2$ ratios contribute to enhanced vascularization (19-21). Furthermore, it has been demonstrated that macrophages are necessary and sufficient to induce the regression of lens vasculature during development and to inhibit abnormal blood vessels in eyes affected by age-related macular degeneration (AMD) $(22,23)$. However, alternative lines of evidence have implicated the promoting role of macrophages in abnormal blood vessel growth in AMD $(24,25)$.

Although CD11c was a marker traditionally associated with dendritic cells (DCs), a recent study found it to be expressed by some macrophages (26). Another recent study by Vianello et al on epicardial adipose tissue considered CD11c-positive cells as M1 state macrophages (27), and the study by Shu et al on the prognostic value of polarized macrophages in patients with hepatocellular carcinoma following curative resection also labeled M1 macrophages with CD11c (28). The study by Lumeng et al reported that CD11c-positive macrophages express pro-inflammatory cytokines, such as tumor necrosis factor- $\alpha$ (TNF- $\alpha$ ) and interleukin (IL)-6, while CD11c-negative ones express arginase 1 and IL-10. They defined the former as M1 and the latter as M2. They also found that most of the CD11c-positive macrophages were CD206-negative, and that most of the CD206-positive macrophages were CD11c-negative, suggesting two distinct subsets of macrophages (29). Therefore, in the present study, we aimed to distinguish retinal macrophages using $\mathrm{CD} 11 \mathrm{c}^{+} \mathrm{F} 4 / 80^{+}$as an $\mathrm{M} 1$ marker and $\mathrm{CD} 206^{+} \mathrm{F} 4 / 80^{+}$as an M2 marker in order to evaluate the phenotypic distribution, gene expression and effector function of retinal macrophages under the condition of oxygen-induced ischemic retinopathy.

\section{Materials and methods}

Mice and ethics statement. All mice used in this study were pathogen-free (SPF) C57BL/6 mice and kept under the conditions in compliance with the ARVO Statement for the use of Animals in Ophthalmic and Vision Research, and the National Institutes of Health Guide for the Care and Use of Laboratory Animals with the approval (SYXK-2012-0026) of the Scientific Investigation Board of Shanghai Jiaotong University School of Medicine, Shanghai, China. All efforts were made to minimize animal suffering.

Mouse model of oxygen-induced retinopathy (OIR). OIR was induced by exposure to high concentrations of oxygen, followed by the return to normal room air; this leads to ischemia. C57BL/6 pups $(n=320)$ were exposed to $75 \%$ oxygen at post-natal day $(\mathrm{P}) 7$ with their nursing mother and returned to room air at $\mathrm{P} 12$, as previously described (30). The oxygen concentration was continuously monitored and controlled with a controller (BioSpherix, Lacona, NY, USA). Age-matched controls were kept in room air.

Wholemount immunofluorescence staining of mouse retinas. Platelet endothelial cell adhesion molecule (PECAM)-1, CD11c and CD206 were selectively stained by in vivo immunostaining as previously described (31). Briefly, the mice were administered an intraocular injection of $1 \mu \mathrm{l}$ primary anti-PECAM-1 (BD Biosciences, San Jose, CA, USA), CD11c (ab11029; Abcam, Cambridge, UK) and CD206 (MCA2235A; AbD Serotec, Kidlington, UK) antibodies under a dissecting microscope with a Harvard Pump Microinjection system (Harvard Apparatus, Holliston, MA, USA) using pulled glass micropipettes (32) and then euthanized $12 \mathrm{~h}$ later. The eyes were enucleated and fixed in $4 \%$ formalin for $5 \mathrm{~h}$. Retinas were dissected, washed and incubated with secondary antibody [Alexa 555-conjugated goat anti-mouse IgG (sc-362267; Santa Cruz Biotechnology, Inc., Santa Cruz, CA, USA) and Alexa 488-conjugated anti-rat IgG (4416s; Cell Signaling Technology, Inc., Danvers, MA, USA)] at room temperature for $45 \mathrm{~min}$ and then flat mounted (4 mice were enrolled in both the OIR and normal control groups for each time point). For anti-mouse F4/80 and FITC-isolectin B4 immunostaining, dissected retinas were incubated with PE-labeled rat anti-mouse F4/80 antibody (12-4801-82; eBioscience, Vienna, Austria) or FITC-isolectin B4 (FL-1201; Vector Laboratories, Inc., Burlingame, CA, USA) at room temperature for $45 \mathrm{~min}$ following fixation in $4 \%$ formalin for $5 \mathrm{~h}$. The samples were imaged with a confocal microscope (Zeiss LSM510 laser scanning confocal microscope; Zeiss, Oberkochen, Germany) or a fluorescence microscope and captured with a digital still camera (Nikon Instruments, Inc., New York, NY, USA). Threedimensional surface rendering of high-resolution confocal z-stacks was carried out with Volocity software (Improvision) (6 mice were enrolled in both the OIR and normal control groups for quantitative wholemount staining and 4 mice were enrolled in both groups for immunofluorescence staining assays at each time point).

Immunohistochemical staining of inducible nitric oxide synthase (iNOS), arginase 1 and isolectin B4. C57BL/6 mice with or without oxygen-induced ischemic retinopathy were euthanized at P13 and P18, and the eyes were rapidly removed and frozen in optimum cutting temperature embedding compound (Miles Diagnostics, Elkhart, IN, USA). The frozen sections $(10-\mu \mathrm{m}$-thick) were thawed, air-dried and fixed in $4 \%$ pre-chilled paraformaldehyde (PFA). The sections were respectively incubated in $5 \%$ bovine serum albumin followed by overnight incubation at $4{ }^{\circ} \mathrm{C}$ with monoclonal rat anti-mouse iNOS antibody (13120s; Cell Signaling Technology, Inc.) and polyclonal rabbit anti-mouse arginase 1 antibody (GTX109242; GeneTex, Irvine, CA, USA). The sections were then respectively incubated in Alexa 555-conjugated anti-rat IgG (sc-3740), or Alexa 555-conjugated anti-goat IgG (sc-362264) (both from Santa Cruz Biotechnology, Inc.) and FITC-labeled isolectin B4 (FL-1201; Vector Laboratories Inc.) for $45 \mathrm{~min}$ at room temperature. Sections were finally stained with DAPI (sc-3598; Santa Cruz Biotechnology, Inc.) for $15 \mathrm{~min}$ at room temperature to display the nuclei. The sections were thoroughly washed with phosphate-buffered saline containing 
$0.25 \%$ Triton X-100 (PBST) between all incubations. The sections were examined under a Nikon microscope and captured as digital files using a Nikon Digital Still Camera DXM 1200 (Nikon Instruments, Inc.) (3 mice were enrolled in both the OIR and normal control groups for each time point).

Reverse transcription-quantitative PCR (RT-qPCR). RNA was isolated from the retinas of mice with OIR and age-matched controls using TRIzol reagent (Invitrogen, Carlsbad, CA, USA) in accordance with the manufacturer's instructions, and as previously described (33). Each sample of total RNA was pre-treated with DNase I (Promega, Fitchburg, WI, USA), and $2 \mu \mathrm{g}$ of each was reverse transcribed into complementary DNA (cDNA) using M-MLV Transcriptase and oligo(dT) primers (Promega), according to the manufacturer's instructions. Quantitative PCR (qPCR) was performed as previously described (34). In brief, each PCR reaction was carried out in a $20 \mu \mathrm{l}$ volume using iQ SYBR-Green Supermix (Roche, Basel, Switzerland) in ABI 7500, and normalized to housekeeping gene, cyclophilin $\mathrm{A}$, which has been reported to be stable under many different conditions and used as a normalization control in previous studies on retinal neovascularization (35-37); 10 mice were enrolled in both the OIR and normal control groups for each time point. Two eyes from one mouse were considered as one sample. The $\Delta \Delta \mathrm{CT}$ method was used for relative quantification. Primer sequences used were designed as follows: murine CD11c forward, 5'-GTGCCCATCAGTTCCTTACA-3' and reverse, 5'-GAGAAGAACTGTGGAGCTGAC-3'; TNF- $\alpha$ forward, 5'-GAACTGGCAGAAGAGGCACT-3' and reverse, 5'-AGGGTCTGGGCCATAGAACT-3'; CD206 forward, 5'-GGAATCAAGGGCACAGAGTTA-3' and reverse, 5'-ATTGTGGAGCAGATGGAA-3'; F4/80 forward, 5'-CGTCAGGTACGGGATGAATATAAG-3' and reverse, 5'-CTATGCCATCCACTTCCAAGAT-3'; iNOS forward, 5'-TCTCССТTТССТСССТТСТT-3' and reverse, 5'-AAAC TCAACCTCCTGACTGAAG-3'; CD163 forward, 5'-CAG ACTGGTTGGAGGAGAAATC-3' and reverse, 5'-TGACTT GTCTCTGGAAGCTG-3'; monocyte chemoattractant protein-1 (MCP-1) forward, 5'-CTCGGACTGTGATGCCTT AAT-3' and reverse, 5'-TAAATGCAAGGTGTGGATCCA-3'); CD16 forward, 5'-CGGGATGTTTGGTTCTTCAATC-3' and reverse, 5'-CATACAGAGAGAGTGAGTGCAAG-3'; cyclophilin A forward, 5'-CAGACGCCACTGTCGCTTT-3' and reverse, 5'-TGTCTTTGGAACTTTGTCTGCAA-3'.

Isolation of mouse retina $C D 11 b^{+}$cells. The retinas of normal mice and those with OIR were carefully dissected out and digested in pre-warmed $16.5 \mathrm{U} / \mathrm{ml}$ papain solution (Worthington, Freehold, NJ, USA) for $30 \mathrm{~min}$ with gentle pipetting, and the cell digestion suspension was then transferred and passed through cell strainers (BD Falcon, Franklin Lakes, NJ, USA) to obtain single cell suspension. The cells were spinned down at $900 \mathrm{rpm}$. After gently removing the supernatant, the cell pellet was suspended with $90 \mu \mathrm{l}$ MACS buffer (BD Biosciences, San Jose, CA, USA), mixed well with $10 \mu 1$ anti-mouse CD11b magnetic beads (Miltenyi Biotec, Bergisch Gladbach, Germany), incubated at $4^{\circ} \mathrm{C}$ for $20 \mathrm{~min}$, washed once and resuspended in $500 \mu \mathrm{l}$ MACS buffer and loaded on a pre-moistured MS column (BD Biosciences,

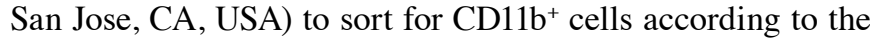
manufacturer's instructions. The selected cells were collected and proceeded to flow cytometric analysis.

Flow cytometric analysis. $\mathrm{CD} 1 \mathrm{~b}^{+}$cells from the retinas of the mice with OIR or the normal mice were resuspended in MACS buffer (BD Biosciences, San Jose, CA, USA) and incubated with PE-conjugated anti-mouse CD11c (12-0114-82; eBioscience), PE-conjugated anti-mouse F4/80 (12-4801-82; eBioscience) and Alexa Fluor 647-conjugated CD206 (MCA2235A647; $\mathrm{AbD}$ Serotec) and the matching control isotype IgG (MCA421; $\mathrm{AbD}$ Serotec) for $30 \mathrm{~min}$ at $4^{\circ} \mathrm{C}$. The cells were then washed and rinsed again and incubated with secondary antibodies for $30 \mathrm{~min}$ at $4^{\circ} \mathrm{C}$. The cells were then washed and re-suspended in FACS buffer (BD Biosciences, San Jose, CA, USA) and analyzed by flow cytometry (BD FACSCalibur flow cytometer; BD Biosciences, Heidelberg, Germany). M1 macrophages were identified as F4/80-positive/CD11c-positive/CD206-negative and M2 macrophages were identified as F4/80-positive/ CD11c-negative/CD206-positive. Data analysis was performed using FlowJo software (Tree Star, Ashland, OR, USA) (6 mice were enrolled in both the OIR and normal control groups for each time point).

Microarray analysis. The high-throughput screening of differential mRNA expression between the mice with OIR and the normal mice were obtained using Affymetrix GeneChip Mouse Genome 4302.0 arrays. Genes were identified as differentially expressed if they exhibited a fold change of at least 1.5 and a $\mathrm{P}$-value $<0.05$. Two retinas from one mouse were considered as one sample (6 mice were enrolled in both the OIR and normal control groups).

Statistical analysis. Quantitative data are presented as the mean values \pm standard deviation (SD). Statistical significance was determined by the two tailed Student's t-test and one-way ANOVA with Student-Newman-Keuls method for multiple comparisons. Differences were considered to be statistically significant at P-values of 0.05, 0.01 and 0.001. Statistical analysis was performed using SAS 9.0 software.

\section{Results}

High levels of mRNAs associated with leukocyte transendothelial migration and cell adhesion in retinas of mice with OIR. The expression changes associated with leukocyte transendothelial migration, cell adhesion and cell communication molecules were assessed at mRNA level by RT-qPCR. Specifically, we measured the expression ratio in the retinas of mice with OIR to that of the normal controls at P15. The significant upregulation of most leukocyte transendothelial migration and cell adhesion molecules was observed in the mice with OIR compared to the normal controls (Fig. 1). Precipitated by hyperoxia, vaso-obliteration occurred. When the mice were returned to room air following exposure to hyperoxia, this caused relative ischemia in the non-perfused retina, and thus neovascularization occurred (30).

Detection of ascendant macrophage influx with the progression of retinal neovascularization $(R N V)$. The retinas from the 


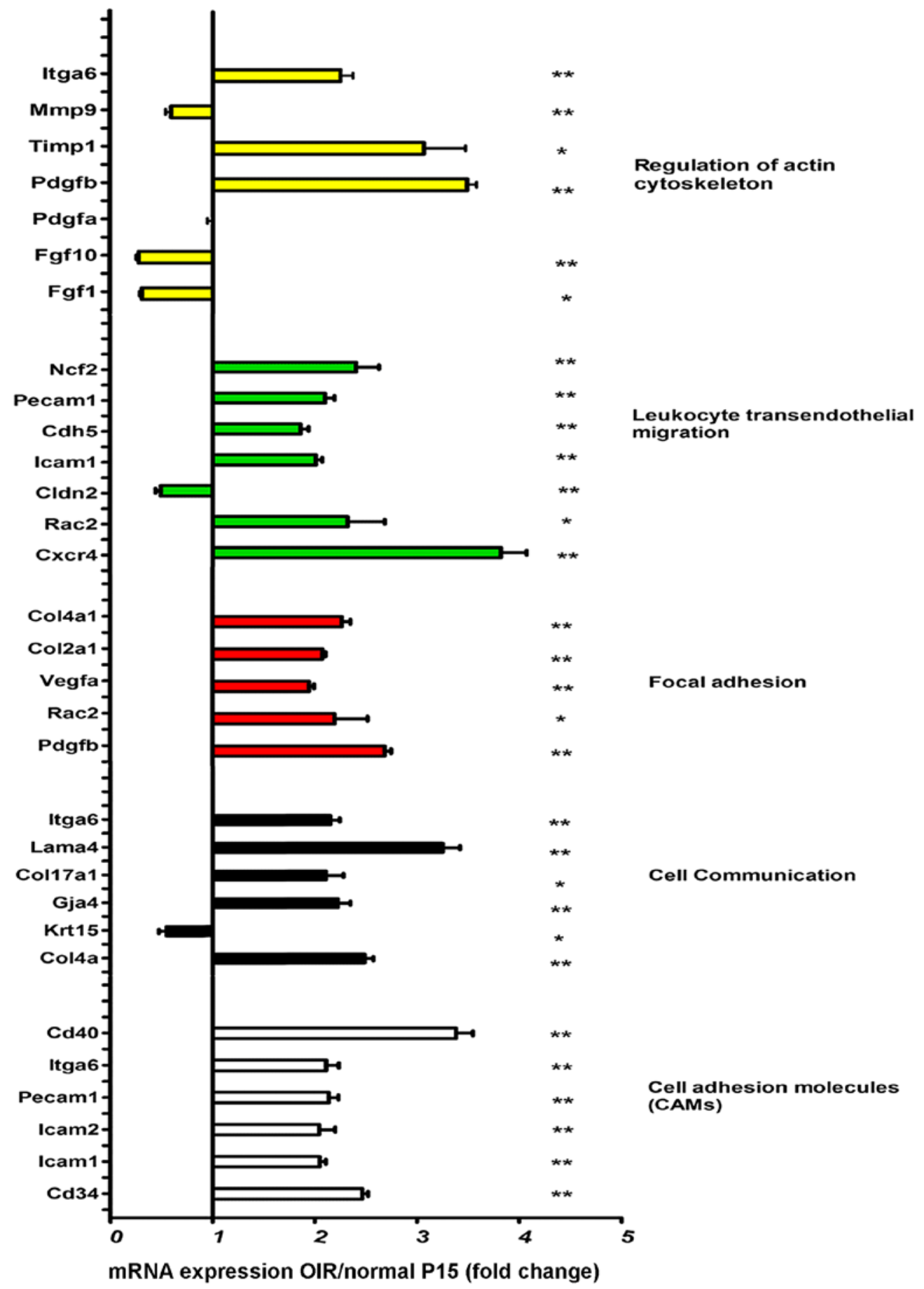

Figure 1. The mRNA expression levels of focal adhesion (red bars)-, cell communication (black bars)-, cell adhesion molecule (CAM) (white bars)- and leukocyte transendothelial migration-related genes (green bars) were mostly upregulated as shown in the graph. The expresion of MMP-9, PDGFa, FGF-1, FGF-10 (genes associated with the regulation of the actin cytoskeleton, yellow bars) slightly decreased, whereas that of other genes shown in this graph increased ( $\mathrm{n}=6 \mathrm{mice} /$ group). OIR, oxygen-induced retinopathy; $\mathrm{P}$, post-natal day. ${ }^{*} \mathrm{P}<0.05$ and ${ }^{* *} \mathrm{P}<0.01$.

mice with OIR and the age-matched controls were dissected, fixed and immunofluorescence stained with FITC-isolectin B4 and PE-labeled F4/80 antibody (Fig. 2). The wholemounts of retinas from mice with oxygen-induced ischemic retinopathy exhibited increased RNV from P13 to P24, with a significant increase at P18, peaking at P21 and subsequently decreasing. Macrophage density increased significantly at P18 and P21 compared to the controls and subsequently decreased. There seemed to be an increasing number of macrophages with the progression of angiogenesis over time.
Decrease in the levels of M1 polarization-associated genes and increase in the levels of M2 polarization-associated genes in retinas from mice with OIR from $\mathrm{P} 13$ to $\mathrm{P} 24$. The retinas from mice with OIR were pooled for RNA extraction from P13 to P24 with the age-matched normal retinas as controls. RNA was then reverse transcribed into cDNA and specific M1 and M2 macrophage polarization-associated genes were evaluated by qPCR (Fig. 3). The expression levels of M1 macrophage polarization-associated genes [iNOS (Fig. 3A), CD16 (Fig. 3B)] were significantly upregulated (approximately 2-3-fold of the 
A

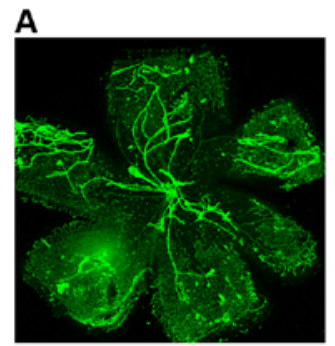

E

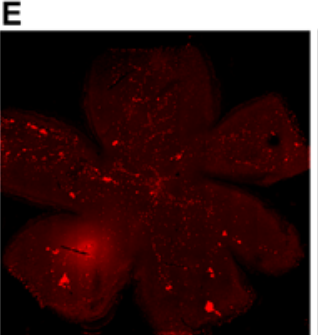

I

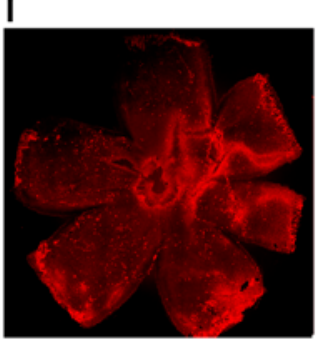

B

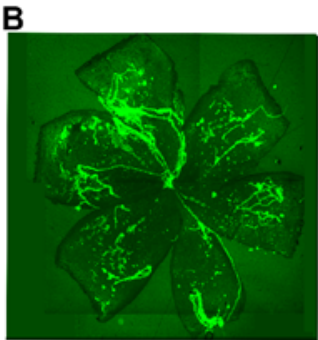

$\mathrm{F}$

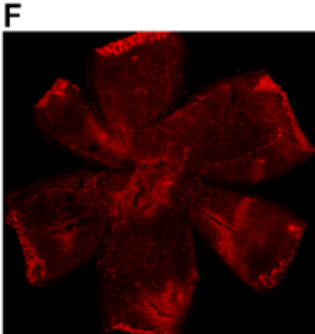

$J$

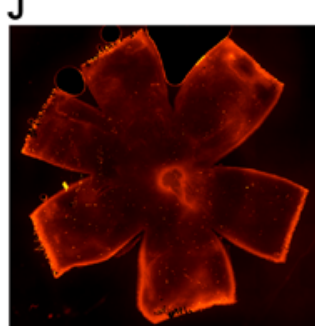

c

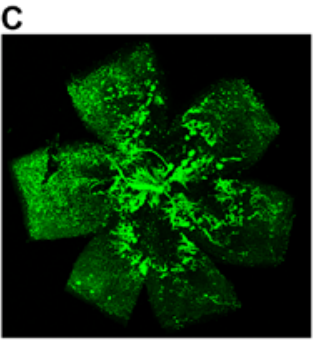

G

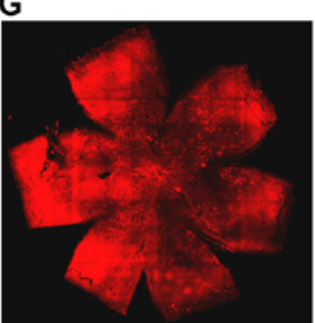

$\mathbf{K}$

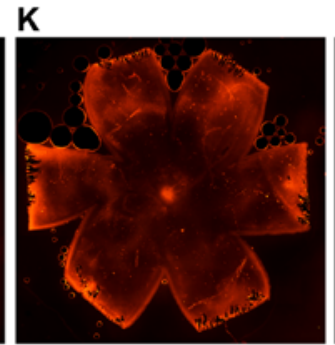

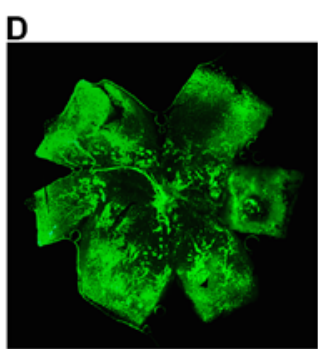

$\mathrm{H}$

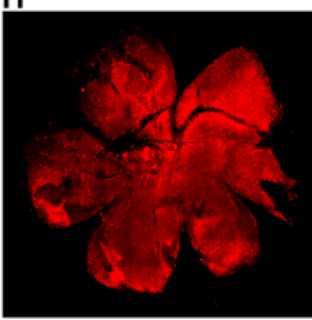

L

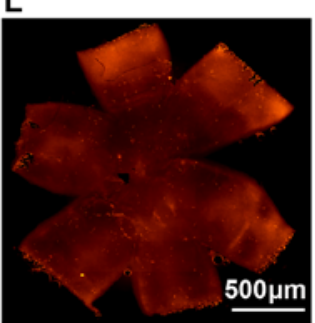

M

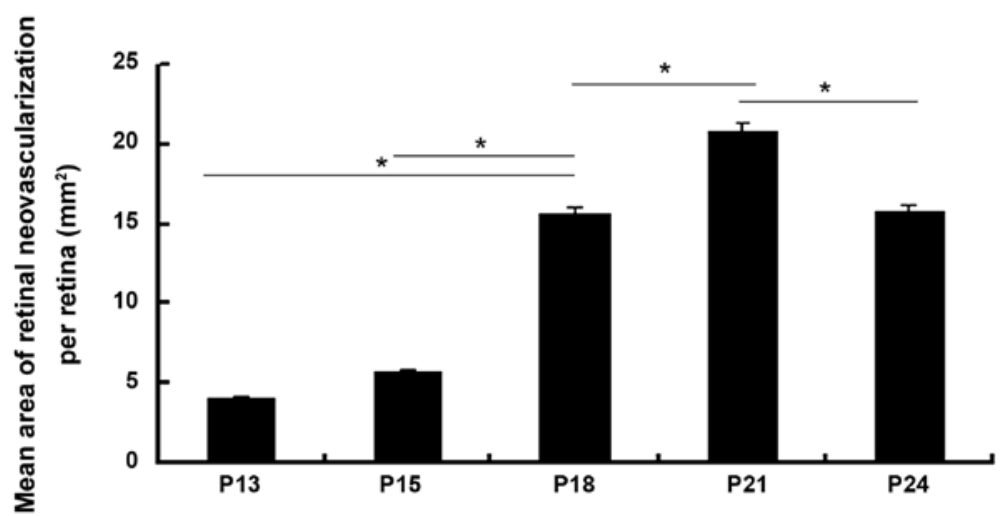

$\mathbf{N}$

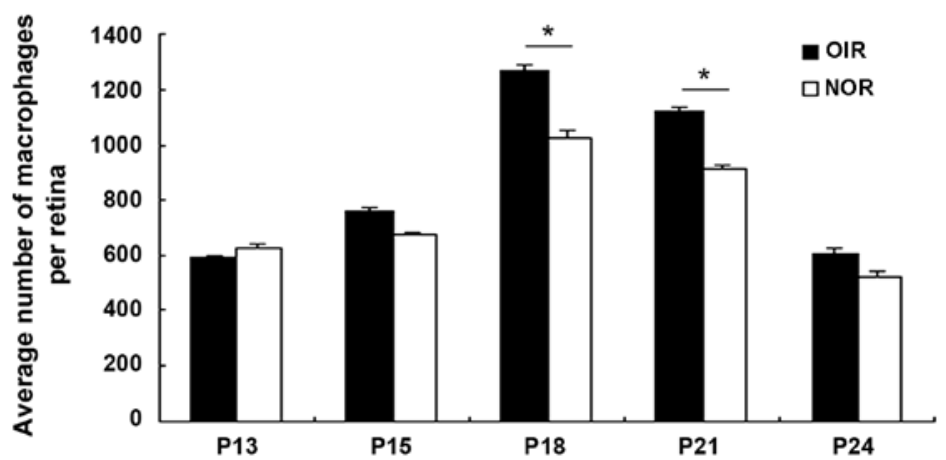

Figure 2. Immunofluorescence staining of retinal wholemounts for vasculature and macrophages in retinas of mice with OIR from P13 to P24 [lectin, green (A-D); F4/80, red (E-H)] and age-matched controls [F4/80, red (I-L)]. Retinas from mice with OIR were stained with FITC-isolectin B4 and PE-labled anti-mouse F4/80 antibody for $45 \mathrm{~min}$ at room temperature. We observed an increasing area of retinal neovascularization (RNV) from P13 to P24, accompanied by the ascending influx of macrophages. Both RNV and macrophages on the surface of the retinas from mice with OIR were estimated at P13 (A and E), P18 (B and F), P21 (C and G) and P24 (D and H). Macrophages influx of the age-matched controls was also examined at P13 (I), P18 (J), P21 (K) and P24 (L). RNV significantly increased from P18, peaking at $\mathrm{P} 21$, and then decreased [(M) $\mathrm{P}<0.05]$, accompanied by a significant macrophage influx ascending at $\mathrm{P} 18$ and $\mathrm{P} 21$ compared to the controls and then decreasing $(\mathrm{N})\left(\mathrm{n}=6\right.$ mice/group). OIR, oxygen-induced retinopathy; NOR, normal; $\mathrm{P}$, post-natal day. ${ }^{*} \mathrm{P}<0.05$.

controls) in the mice with OIR at P15. Although relatively high levels of TNF- $\alpha$ (Fig. 3D) and CD163 (Fig. 3E) (an M2 macro- phage polarization-associated marker) were observed, no statistical significance was obtained. An increased expression 

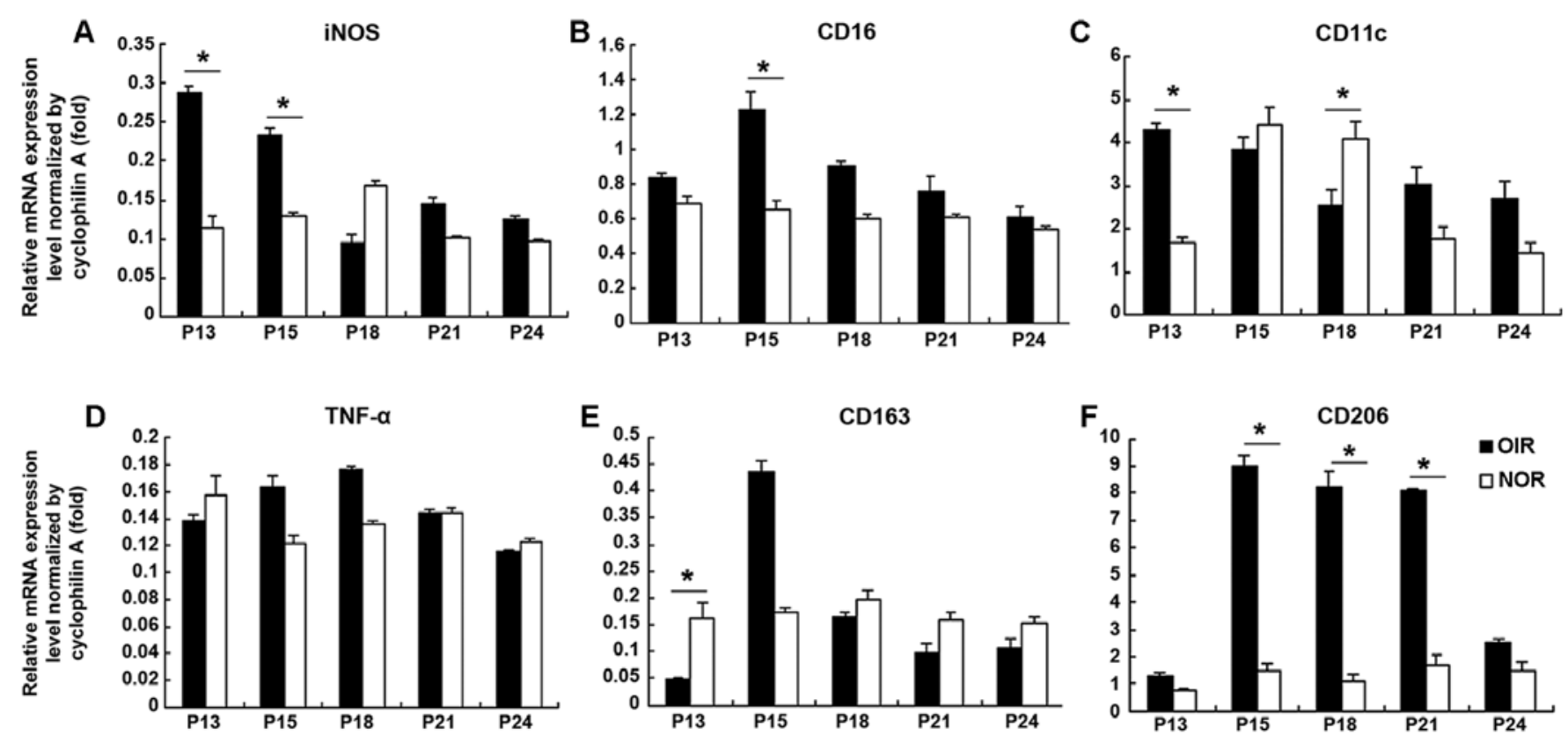

Figure 3. The mRNA expression of macrophage polarization-associated genes in mice with OIR and age-matched normal controls. The mRNA levels of (A) iNOS, (B) CD16, (C) CD11c, (D) tumor necrosis factor- $\alpha$ (TNF- $\alpha$ ), (E) CD163 and (F) CD206 were compared between the mice with OIR and the normal controls from P13 to P24 ("P<0.05) (n=10 mice/group). OIR, oxygen-induced retinopathy; NOR, normal; P, post-natal day. " $\mathrm{P}<0.05$.

of CD11c (Fig. 3C) was observed in the mice with OIR soon after returning to room air at P13 (approximately 2.5 -fold compared to the normal controls); however, CD11c expression decreased at P18 and reached levels close to those of the normal controls. The CD206 expression level in the mice with OIR was upregulated from P13 until P21 (approximately 8-fold compared to the normal controls at P18 and P21), but decreased at P24, suggesting a switch towards M2 polarization during the process.

Close association of macrophages with RNV at different time points. Retina flat mounts from the mice with OIR and the controls were immunofluorescence stained with PE-labeled F4/80 antibody and FITC-isolectin B4. In the mice with oxygen-induced ischemic retinopathy, the macrophages were located in close proximity to the area affected by RNV, as shown by immunofluorescence staining of the retinas (Fig. 4A-M). Compared with the moderate number of macrophages observed in the retinas of normal mice (Fig. 4N-Y), the retinas from the mice with ischemic retinopathy exhibited a high density of macrophages neighboring the RNV (Fig. 4A'-F' and $\mathrm{N}^{\prime}-\mathrm{S}^{\prime}$ ), indicating a potential role of macrophages in RNV.

Polarization of macrophages towards the M2 subtype during the progression of $R N V$. The numbers of macrophages in the retinas of mice with OIR and normal mice were analyzed by flow cytometry at different time points. F4/80-positive cells were gated out from the live cells and we used CD11c and CD206 as markers to identify M1 or M2 macrophages. $\mathrm{F} 4 / 80^{+}, \mathrm{CD} 11 \mathrm{c}^{+}$and $\mathrm{CD} 206^{-}$cells are marked as M1-positive cells, and $\mathrm{F} 4 / 80^{+}$, CD11c ${ }^{-}$and $\mathrm{CD} 206^{+}$cell are marked as M2-positive cells. The cell distribution patterns in the retinas from the normal mice, and the mice with OIR during the early stage (P13) and later stage (P21) are shown in Fig. 5B. The M2 macrophage number (Fig. 5E) in the mice with OIR at P12 and P13 was lower than that of the normal group; however, it then increased sharply after the the mice with OIR were returned to normal air, and remained at a relatively high level at P15-P21, returning to normal levels at P24. The M1 macrophage number (Fig. 5D) increased at P13, and rapidly decreased at P18; at P24, it returned to relatively normal levels in the mice with OIR. The F4/80 $0^{+}$macrophage numbers (Fig. 5C) in the mice with OIR rapidly increased from P15 until later on. A sharp decrease in the M1/M2 ratio of macrophages was thus suggested in the mice with OIR, indicating that there was a shift in macrophage polarization towards the M2 subtype. At P24, the M1, M2, M1/M2 distribution pattern returned to normal.

Contributions of M1 and M2 macrophages to the different steps of $R N V$. Arginase 1 and iNOS were stained to indicate M2 and M1 polarized macrophages as previously reported (38). A relatively high expression level of iNOS was observed at P13 in the eyes of the mice with OIR, while a relatively high expression level of arginase 1 was identified at P18 (Fig. 6, arrowheads) Although a close association between iNOS and arginase 1 expression was identified with vascular formation, co-localization was not identified in these sections. Furthermore, differential expression patterns of iNOS and arginase 1 during the progression of retinopathy may indicate the different roles that M1 and M2 macrophages play in this process.

Differential effects of M1, M2 macrophages during the proces of $R N V$. To explore the phenotypic and functional differences of M1 and M2 macrophages, the retinas of mice with 


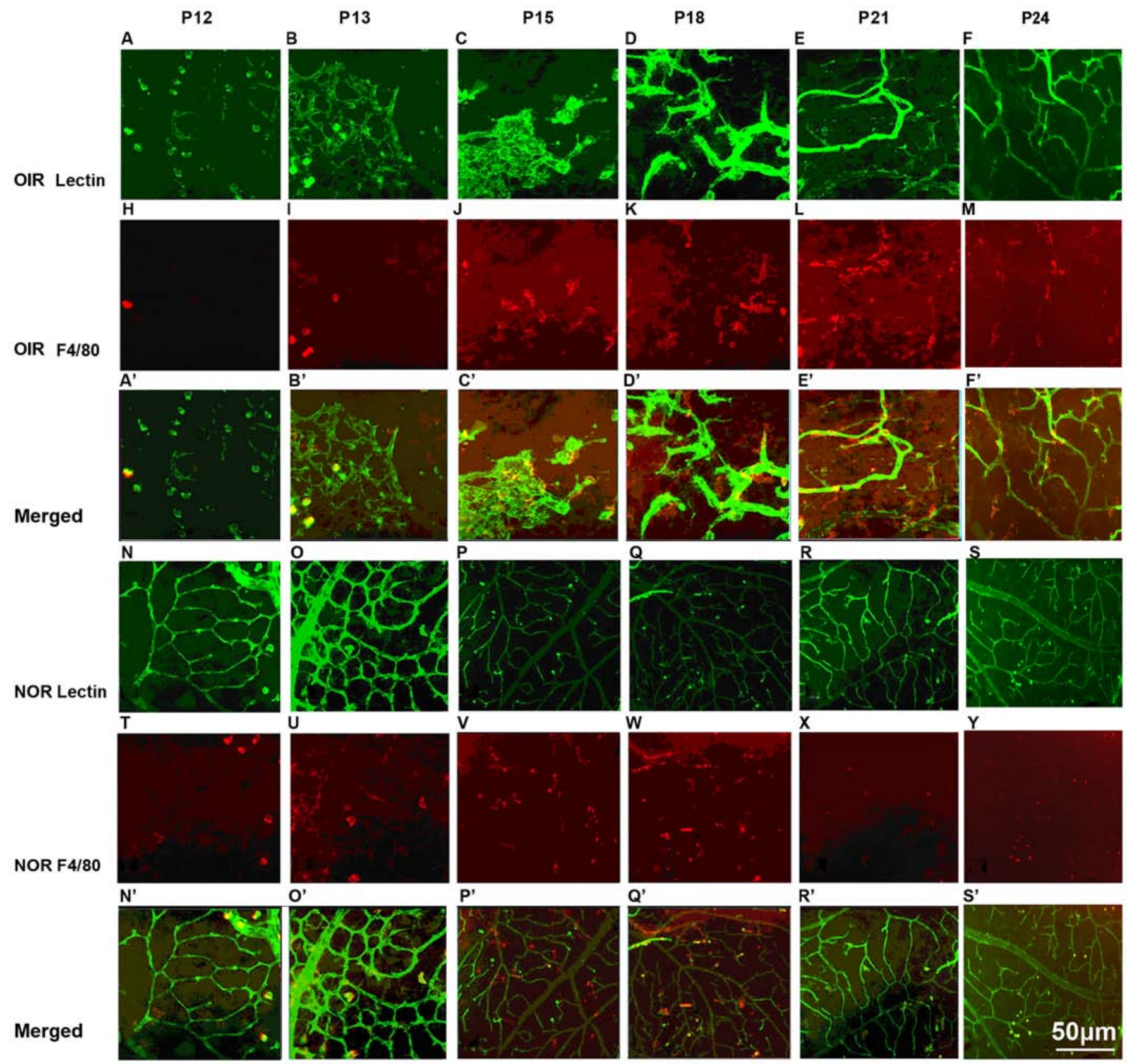

Figure 4. Immunofluorescence staining for retinal vasculature (lectin, green) and macrophages (F4/80, red) of retinas from mice with OIR and age-matched normal controls at different time points. The eyes of mice with OIR and age-matched control mice were fixed and retinas were dissected, incubated in FITC-isolectin B4 and PE-labeled anti-mouse F4/80 for $45 \mathrm{~min}$ at room temperature. Retinas were then flat-mounted and examined by fluorescence microscopy. Ischemic retinas from mice with OIR exhibited small tufts and bulbous networks of neovascularization from the retinal capillary bed (A-F) from P12 to P24, and a close association with macrophages was observed by counterstaining with F4/80 [(H-M) and ( $\left.\mathrm{A}^{\prime}-\mathrm{F}^{\prime}\right)$ merged images]. Clear vasculature of normal mice was examined (N-S) counterstained with F4/80 [(T-Y) and (N'-S') merged images] (n=4 mice/group). OIR, oxygen-induced retinopathy; NOR, normal; P, post-natal day.

OIR at P13 and P18 were analyzed. Retinal flat mounts were immunofluorescence stained with isolectin B4 and CD11c or CD206 (Fig. 7). Laser scanning confocal imaging revealed the co-localization of CD11c-positive cells or CD206-positive cells and endothelial cells. F4/80-positive cells were generally stained with CD11c at P13 and with CD206 at P18 (Fig. 7J-O). This illustrated that CD11c-positive cells interacted with endothelial tip cells at the vascular front at early stage, while CD206-positive cells embraced the emerging vessels and bridged the neighboring vessel sprouts, suggesting a promotive function for tip cell fusion at the later stage.

\section{Discussion}

It has been well established that blood vessels grow into networks through a process involving sprouting, anastomosis and maturation (39). Immune vascular interactions can play an important role in regulating angiogenesis in the eye $(22,40,41)$. Accumulating evidence has implicated a critical role for macrophages in this process. Gao et al (42) studied the role of macrophages in vasculogenesis of RNV in a mouse model of OIR by depleting macrophages using an intra-peritoneal injections of of clodronate-liposomes at P9, P11, P13 and 

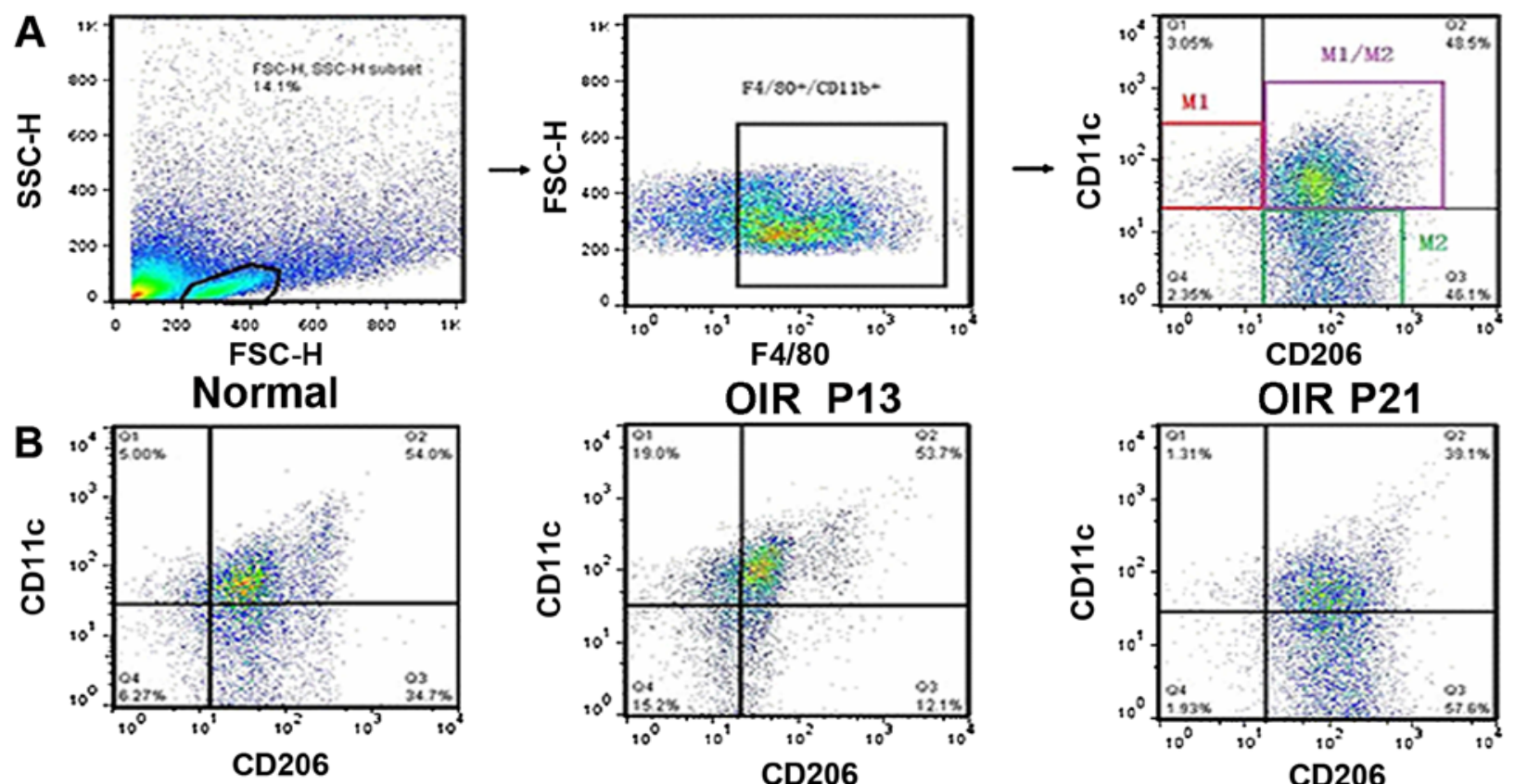

OIR P13
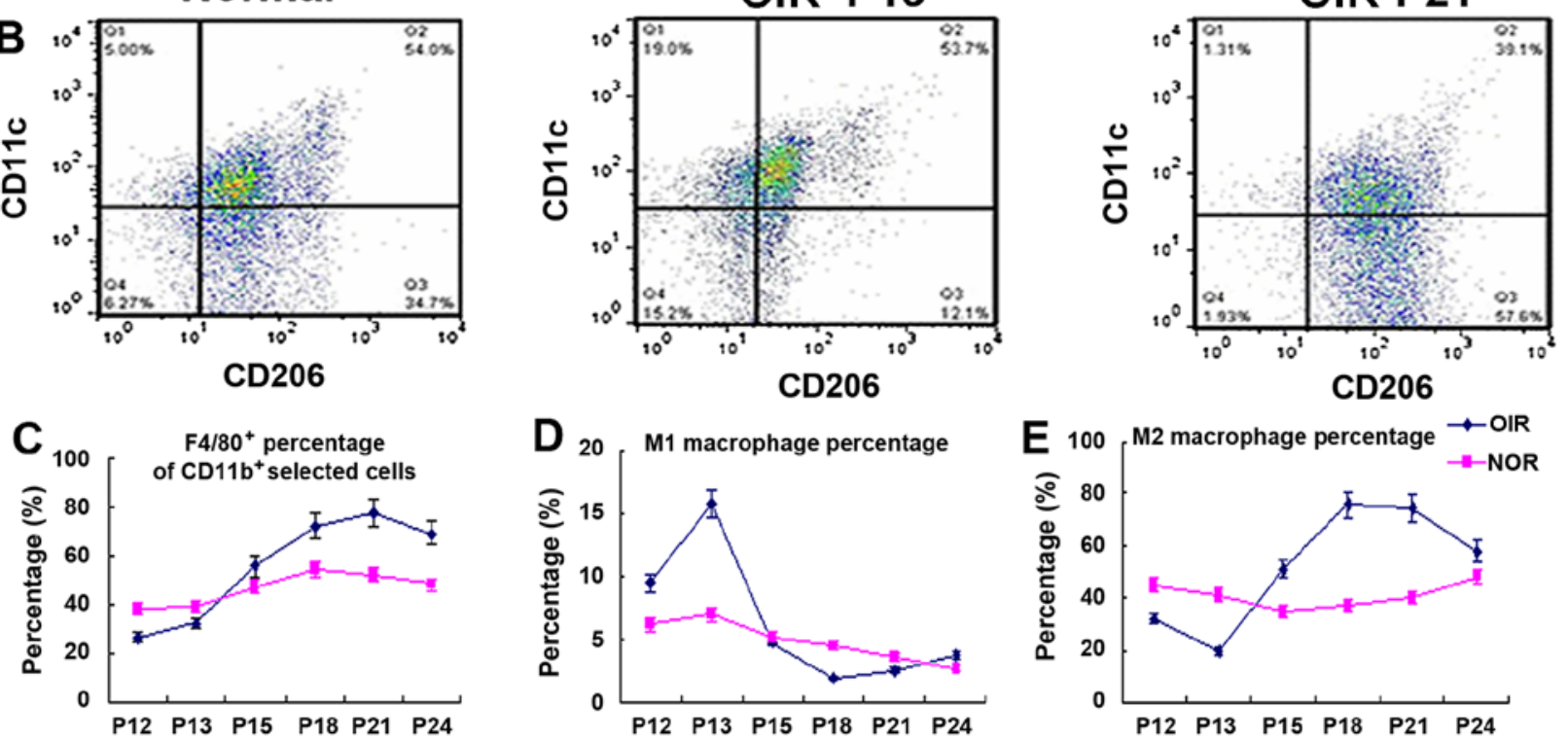

Figure 5. Flow cytometric analysis of mice with OIR at different time points. (A) The selection of M1- or M2-positive cells. In brief, we first gated out the live cells, and then gated out the F4/80-positive cells. In this subgroup, we used CD11c and CD206 as markers to identify M1 or M2 macrophages. F4/80 ${ }^{+}$, CD11 ${ }^{+}$, CD206 cells are markered as $\mathrm{M} 1$ positive cells, $\mathrm{F} 4 / 80^{+}, \mathrm{CD} 11 \mathrm{c}^{-}, \mathrm{CD} 206^{+}$cells are marked as M2-positive cells. (B) The cell distribution pattern in normal mice and mice with OIR in the early stage (P13) and later stage (P21). (C-E) The percentage of total F4/80+ macrophages, the M1 macrophages, and the M2 macrophage in mice with OIR and the age-matched controls. M2 macrophage number (E) in the mice with OIR at P12 and P13 was lower than that of the normal group, but then increased sharply after the mice with OIR were returned to normal air, and remained at a relatively high level at P15-P21, returning to normal levels at P24. The M1 macrophage number (D) increased at P13, and rapidly decreased at P18, and at P24 it returned to relatively normal levels. The total number of F4/80 macrophages (C) in mice with OIR at P12 and P13 was lower than that of the age-matched control mice, but it rapidly increased at P15 and onwards; we observed a sharp decrease in the M1/M2 cells; the macrophages in the mice with OIR were polarized towards the M2 subtype macrophage. At P24, the M1, M2, M1/M2 distribution pattern returned to normal ( $\mathrm{n}=6$ mice/group). OIR, oxygen-induced retinopathy; NOR, normal; P, post-natal day.

P15. They found that macrophage depletion (the quantities of retinal macrophages were reduced by approximately $80 \%$ and the mRNA expression of F4/80 also decreased at P17) did not affect the vaso-obliterative phase, but reduced the retinal avascular area and neovascular tufts during the neovascularization phase in OIR. Their findings demonstrated that the depletion of macrophages markedly decreased OIR severity, angiogenic cytokines and extracellular matrix degradation at P17, causing growth restriction of pathologic RNV (42). It has been demonstrated that cytokines can influence the macrophage-mediated regulation of angiogenesis. In a model of laser-induced CNV, mice that lacked IL-10 (IL-10 $\left.{ }^{-/}\right)$were significantly impaired in their ability to generate CNV. In the eye, IL-10 promotes angiogenesis by altering macrophage function. The polarization of macrophages can play a pivotal role in determining the ultimate effector function of these cells (43).

The present study demonstrated that the retinas of mice with OIR expressed high levels of mRNAs associated with leukocyte transendothelial migration and cell adhesion, indicating an active interplay between inflammation and angiogenesis under conditions of OIR in this animal model. Sato et al analyzed comprehensive gene-expression profiles in murine OIR and indicated that genes associated with inflammation expressed high values from the beginning to the late stages of OIR, which preceded the angiogenesis and the upregulation of angiogenic genes (44). Furthermore, macrophage activation signatures defined in vitro have been reported to be highly influenced by factors often overlooked in vivo, such as cell migration, adhesion and chemoattractants (45). This expression pattern suggests an increase influx of macrophages along with the neovascularization process that was demonstrated by our immunofluorescence retinal staining, suggesting a close correlation between macrophages and the neovascularization process.

In order to investigate the phenotype of the increased inflammatory cells and their correlation with RNV, we performed qPCR for inflammation-associated genes and immunofluorescence staining for retinal vessels together with macrophages from P12 to P24. The results of qPCR suggested 

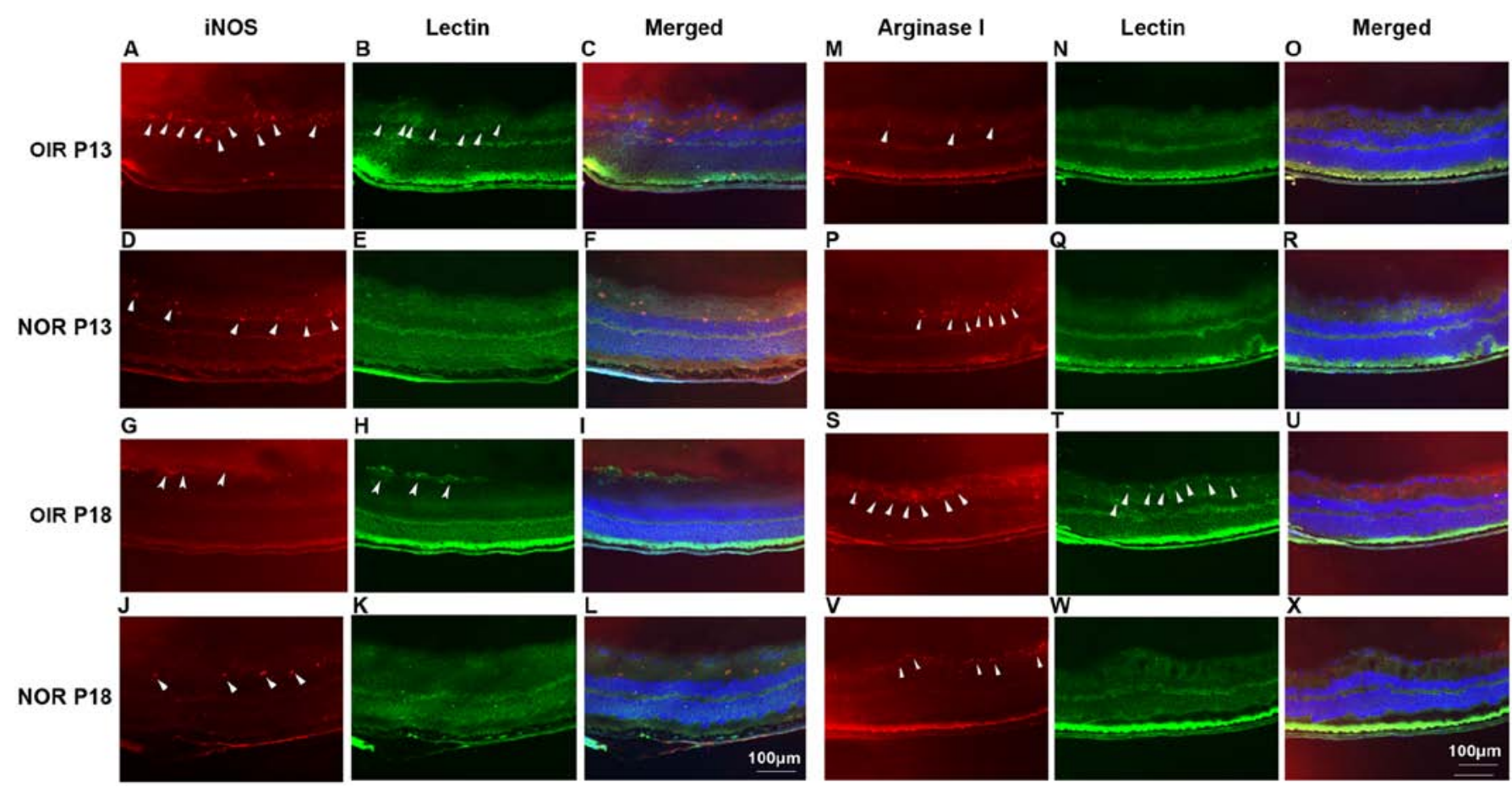

Figure 6. Immunofluorescence staining of iNOS/arginase 1 (red) and isolectin B4 (green) in the eyes of normal mcie and mice with OIR at P13 and P18. C57BL/6 mice with or without ischemic retinopathy were euthanized at P13 and P18, and their eyes were rapidly removed and frozen sections were created. After staining with primary anti-mouse iNOS (A, D, G and J) and arginase 1 (M, P, S and V) antibody, followed by Alexa-555 labeled secondary antibody, and FITC-isolectin B4 (B, E, H and K; N, Q, T and W) the sections were examined under fluorescent microscopy. Merged images are shown in panels C, F, I and L for iNOS and lectin B4 and in panels $\mathrm{O}, \mathrm{R}, \mathrm{U}$ and $\mathrm{X}$ for arginase 1 and lectin B4. Nuclei were stained with DAPI (blue) (n=3 mice/group). OIR, oxygen-induced retinopathy; NOR, normal; $\mathrm{P}$, post-natal day.

a significant increase in the expression of the macrophage marker, F4/80, accompanied with upregulated expression levels of M1-associated genes. The staining results indicated a close association of macrophages with protruding bulbous networks of neovascularization in ischemic retinas from the mice. Further assays to classify the infiltrated macrophages demonstrated enhanced M1 phenotype polarization at P13 and enhanced M2 phenotype polarization at P15-P18, indicating a shift in the macrophage polarization towards the M2 subtype. In addition, Spiller et al demonstrated that M1 macrophages appear at early stages of wound healing (1-3 days) and are later replaced by M2 macrophages (4-7 days) (46). Taking into consideration the findings of Sato et al that inflammation-associated genes are upregulated prior to the formation of neovascularization, at P12 and P13, and angiogenesis-associated genes were mostly upregulated at P16 and P17, when neovascularization became most noticeable (44), our results showed good consistency with the respective roles of M1 and M2 macrophages previously reported.

The distinct features of M1 and M2 macrophages phenotypically and functionally in RNV has attracted increasing interest. Marchetti et al demonstrated that human umbilical cord blood-derived myeloid progenitor cells differentiated in vivo into M2 macrophages and induced resident macrophages to M2 polarization. These M2 polarized macrophages prevented neovascularization and maintained the stabilization of the ischemic retina by modulating the inflammatory responses, reducing oxidative stress and promoting tissue repair (47). On the other hand, the study by Zhou et al showed that M2 macro- phages, rather than M1 macrophages, played an important role in promoting pathological neovascularization and inhibiting physiological revascularization (48). In this study, to investigate the potential role of the two phenotypes, retina flat mounts of OIR mice were stained and scanned by confocal microscopy. The results illustrated that M1 macrophages interacted with endothelial tip cells, while M2 macrophages promoted cell fusion that facilitated anastomosis. Similar findings were also observed by Fantin et al in the nervous system (49). The ablation of macrophages resulted in reduced vessel intersections, providing evidence that macrophages play an active role in vessel anastomosis (49). Caicedo et al found extensive macrophage recruitment in the retina under $\mathrm{CNV}$, with infiltrating macrophages predominated over resident microglia, suggesting that macrophages were closely associated with retinal blood vessels (50). Cao et al found an increased number of M2 macrophages compared to M1 macrophages in normal aging eyes (51). Dace et al demonstrated that IL-10 and hypoxia unmasks the pro-angiogenic phenotype in a macrophage (23). These mouse model experiments demonstrated that macrophages had shown 'wound healing' and 'angiogenesis' gene expression signatures (52).

This study demonstrated the specific contributing roles of M1, M2 macrophages in different steps of RNV following OIR. During this angiogenic process, M1 macrophages dominated the first 2-3 days following OIR, while M2 macrophages represented the overwhelming macrophage subset thereafter, which is in accordance with the studies of post-myocardial infarction and wound healing process $(38,53,54)$. Recently, Ma et al 

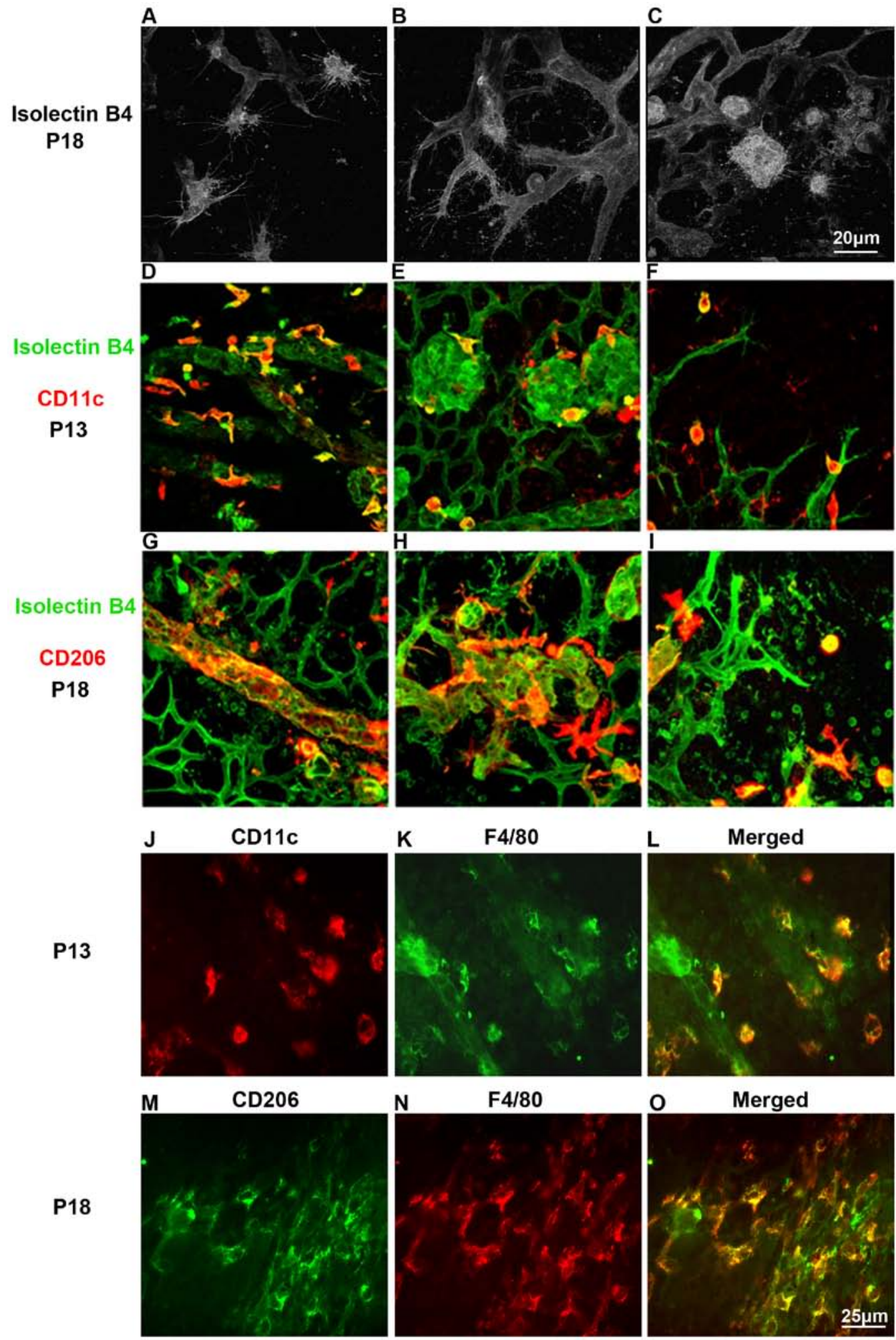

Figure 7. M1, M2 macrophages contribute to the different steps of retinal neovascularizaion (RNV). RNV at P13 in the retinas of mice with OIR. Retinas were stained with isolectin B4 and CD11c, and at P18 retinas were stained with isolectin B4 and CD206. Flatmounts were examined by laser scanning confocal microscopy. Isolectin B4-positive endothelial tip cells and macrophages are shown in (A-C). Yellow indicates the co-localization of endothelial cells and CD11c-positive cells [M1 macrophages (D-F)] or CD206-positive cells [M2 macrophages (G-I)]. Costaining of CD11c with F4/80 at P13 is shown in (J-L) and CD206 with F4/80 at P18 in (M-O). CD11c-positive cells interact with endothelial tip cells at the vascular front, while CD206-positive cells embrace the emerging vessels and bridge the neighboring vessel sprouts, suggesting a promotive function for tip cell fusion ( $\mathrm{n}=4$ mice/group). OIR, oxygen-induced retinopathy; NOR, normal; P, post-natal day.

investigated subretinal fluid and surgically dissected retrolental membranes from patients with advanced ROP and demonstrated that the microenvironment in eyes with advanced ROP is both pro-angiogenic and pro-inflammatory, with the preponderance of M1 over M2 (55). In addition, the M1 macrophage-secreted cytokines, TNF- $\alpha$ and VEGF, facilitate these cells to promote blood vessel sprouting by interaction with endothelial tip cells, whereas M2 macrophages promote anastomosis, which 
has been reported to be associated with Notch1 signaling; however, the secreted factors remain to be clarified (56). These results, together with the continued presence of M1 and M2 macrophages contributing to neovascularization suggest the coordinated involvement of both subsets of macrophages guides retinal new blood vessel formation.

The present study provides an outlook of macrophage polarization during OIR, in an aim to shed light on the therapeutic potential target of macrophages in the treatment of neovascular eye diseases in addition to anti-VEGF therapy. However, there are still disadvantages in this study. First, there are different subgroups within M2 macrophages. In addition to traditional M2 macrophages, called M2a, macrophages stimulated with IL-10 are classified as M2c. Yet the different function of these two subsets in RNV remains unclear. Further studies are necessary to investigate their distinctions in this process. Second, clearly it is the combined effect of cytokine profiles that drives the angiogenic phenotype of macrophages. For instance, TNF- $\alpha$ has been shown to be pro-angiogenic in cancers, but it is also secreted at functionally significant levels by the antiangiogenic M1 macrophages (57). CD163 was considered as the $\mathrm{M} 2$ phenotype, but $\mathrm{CD}_{163^{+}}$macrophages have been reported to secret inflammatory cytokines in response to biomaterials in vitro and patients with psoriasis $(58,59)$. As a result, the interplay between M1 and M2 macrophages in angiogenesis, particularly the combined effects of timing, calls for further attention. In addition, other animal models in which retinopathy is not healed by neovascularization need to be investigated to study further the macrophage response.

We are now at a circumstance where identifying additional VEGF-independent pathways that trigger abnormal angiogenesis in the eye is critical. Ma et al suggested that anti-inflammatory therapy and the promotion of M2 activation over M1 activity should be included in addition to the surgical removal of the fibrovascular membranes and antiangiogenic therapy to cope with advanced ROP based on their findings (55). Furthermore, it is also important to identify safe and effective modalities of the targeted delivery of therapeutic agents to the posterior compartment of the eye to maximize sustained treatment effects and minimize local or systemic adverse events. Macrophages, as the members of the innate immune system, are believed to be the potential target for researchers to exert control and to modulate ocular neovascularization.

In conclusion, the findings of this study demonstrate that M1 and M2 macrophages play an active role in OIR by contributing to different steps of RNV. Thus, tissue macrophages may be considered as a potential target for the anti-angiogenic therapy of ocular neovascularization diseases.

\section{Acknowledgements}

The study was supported by grants from the National Nature Science Foundation of China, 81470639 and 81570853; the Shanghai Nature Science Foundation Grant 14411968400; the Shanghai Charity Cancer Research Center Program 2013, and 2015 Doctoral Innovation Fund Projects BXJ201414 from Shanghai Jiaotong University School of Medicine, China. The authors would like to thank Professor Honglin Wang for assisting with the flow cytometry experiment.

\section{References}

1. Hiratsuka S, Minowa O, Kuno J, Noda T and Shibuya M: Flt-1 lacking the tyrosine kinase domain is sufficient for normal development and angiogenesis in mice. Proc Natl Acad Sci USA 95: 9349-9354, 1998.

2. Sadiq MA, Hanout M, Sarwar S, Hassan M, Do DV, Nguyen QD and Sepah YJ: Platelet derived growth factor inhibitors: A potential therapeutic approach for ocular neovascularization. Saudi J Ophthalmol 29: 287-291, 2015.

3. Rofagha S, Bhisitkul RB, Boyer DS, Sadda SR and Zhang K; SEVEN-UP Study Group: Seven-year outcomes in ranibizumabtreated patients in ANCHOR, MARINA, and HORIZON: a multicenter cohort study (SEVEN-UP). Ophthalmology 120: 2292-2299, 2013

4. Comparison of Age-related Macular Degeneration Treatments Trials (CATT) Research Group, Martin DF, Maguire MG, Fine SL, Ying GS, Jaffe GJ, Grunwald JE, Toth C, Redford M and Ferris FL III: Ranibizumab and bevacizumab for treatment of neovascular age-related macular degeneration: two-year results. Ophthalmology 119: 1388-1398, 2012.

5. Newman AC and Hughes CC: Macrophages and angiogenesis: a role for Wnt signaling. Vasc Cell 4: 13, 2012.

6. Ligresti G, Aplin AC, Zorzi P, Morishita A and Nicosia RF: Macrophage-derived tumor necrosis factor-alpha is an early component of the molecular cascade leading to angiogenesis in response to aortic injury. Arterioscler Thromb Vasc Biol 31: 1151-1159, 2011.

7. Wu H, Xu JB, He YL, Peng JJ, Zhang XH, Chen CQ, Li W and Cai SR: Tumor-associated macrophages promote angiogenesis and lymphangiogenesis of gastric cancer. J Surg Oncol 106: 462-468, 2012.

8. Stein M, Keshav S, Harris N and Gordon S: Interleukin 4 potently enhances murine macrophage mannose receptor activity: a marker of alternative immunologic macrophage activation. J Exp Med 176: 287-292, 1992.

9. Ding Y, Song N and Luo Y: Role of bone marrow-derived cells in angiogenesis: Focus on macrophages and pericytes. Cancer Microenviron 5: 225-236, 2012.

10. Kigerl KA, Gensel JC, Ankeny DP, Alexander JK, Donnelly DJ and Popovich PG: Identification of two distinct macrophage subsets with divergent effects causing either neurotoxicity or regeneration in the injured mouse spinal cord. J Neurosci 29: 13435-13444, 2009.

11. Ashcroft GS, Jeong MJ, Ashworth JJ, Hardman M, Jin W, Moutsopoulos N, Wild T, McCartney-Francis N, Sim D, McGrady G, et al: Tumor necrosis factor-alpha (TNF- $\alpha$ ) is a therapeutic target for impaired cutaneous wound healing. Wound Repair Regen 20: 38-49, 2012.

12. Khallou-Laschet J, Varthaman A, Fornasa G, Compain C, Gaston AT, Clement M, Dussiot M, Levillain O, Graff-Dubois S, Nicoletti A, et al: Macrophage plasticity in experimental atherosclerosis. PLoS One 5: e8852, 2010.

13. Kitajewski J: Wnts heal by restraining angiogenesis. Blood 121: 2381-2382, 2013.

14. Badylak SF, Valentin JE, Ravindra AK, McCabe GP and Stewart-Akers AM: Macrophage phenotype as a determinant of biologic scaffold remodeling. Tissue Eng Part A 14: 1835-1842, 2008.

15. Brown BN, Valentin JE, Stewart-Akers AM, McCabe GP and Badylak SF: Macrophage phenotype and remodeling outcomes in response to biologic scaffolds with and without a cellular component. Biomaterials 30: 1482-1491, 2009.

16. Fishman JM, Lowdell MW, Urbani L, Ansari T, Burns AJ, Turmaine M, North J, Sibbons P, Seifalian AM, Wood KJ, et al: Immunomodulatory effect of a decellularized skeletal muscle scaffold in a discordant xenotransplantation model. Proc Natl Acad Sci USA 110: 14360-14365, 2013.

17. Madden LR, Mortisen DJ, Sussman EM, Dupras SK, Fugate JA, Cuy JL, Hauch KD, Laflamme MA, Murry CE and Ratner BD: Proangiogenic scaffolds as functional templates for cardiac tissue engineering. Proc Natl Acad Sci USA 107: 15211-15216, 2010.

18. Zhang L, Cao Z, Bai T, Carr L, Ella-Menye JR, Irvin C, Ratner BD and Jiang S: Zwitterionic hydrogels implanted in mice resist the foreign-body reaction. Nat Biotechnol 31: 553-556, 2013.

19. Bota PC, Collie AM, Puolakkainen P, Vernon RB, Sage EH, Ratner BD and Stayton PS: Biomaterial topography alters healing in vivo and monocyte/macrophage activation in vitro. J Biomed Mater Res A 95: 649-657, 2010. 
20. Tolg C, Hamilton SR, Zalinska E, McCulloch L, Amin R, Akentieva N, Winnik F, Savani R, Bagli DJ, Luyt LG, et al: A RHAMM mimetic peptide blocks hyaluronan signaling and reduces inflammation and fibrogenesis in excisional skin wounds. Am J Pathol 181: 1250-1270, 2012.

21. Tous E, Weber HM, Lee MH, Koomalsingh KJ, Shuto T, Kondo N, Gorman JH III, Lee D, Gorman RC and Burdick JA: Tunable hydrogel-microsphere composites that modulate local inflammation and collagen bulking. Acta Biomater 8: 3218-3227, 2012.

22. Apte RS, Richter J, Herndon J and Ferguson TA: Macrophages inhibit neovascularization in a murine model of age-related macular degeneration. PLoS Med 3: e310, 2006.

23. Dace DS, Khan AA, Kelly J and Apte RS: Interleukin-10 promotes pathological angiogenesis by regulating macrophage response to hypoxia during development. PLoS One 3: e3381, 2008

24. Espinosa-Heidmann DG, Suner IJ, Hernandez EP, Monroy D, Csaky KG and Cousins SW: Macrophage depletion diminishes lesion size and severity in experimental choroidal neovascularization. Invest Ophthalmol Vis Sci 44: 3586-3592, 2003.

25. Sakurai E, Anand A, Ambati BK, van Rooijen N and Ambati J: Macrophage depletion inhibits experimental choroidal neovascularization. Invest Ophthalmol Vis Sci 44: 3578-3585, 2003.

26. Gautier EL, Shay T, Miller J, Greter M, Jakubzick C, Ivanov S, Helft J, Chow A, Elpek KG, Gordonov S, et al; Immunological Genome Consortium: Gene-expression profiles and transcriptional regulatory pathways that underlie the identity and diversity of mouse tissue macrophages. Nat Immunol 13: 1118-1128, 2012

27. Vianello E, Dozio E, Arnaboldi F, Marazzi MG, Martinelli C, Lamont J, Tacchini L, Sigrüner A, Schmitz G and Corsi Romanelli MM: Epicardial adipocyte hypertrophy: Association with M1-polarization and toll-like receptor pathways in coronary artery disease patients. Nutr Metab Cardiovasc Dis 26: 246-253, 2016.

28. Shu QH, Ge YS, Ma HX, Gao XQ, Pan JJ, Liu D, Xu GL, Ma JL and Jia WD: Prognostic value of polarized macrophages in patients with hepatocellular carcinoma after curative resection. J Cell Mol Med 20: 1024-1035, 2016.

29. Lumeng CN, DelProposto JB, Westcott DJ and Saltiel AR Phenotypic switching of adipose tissue macrophages with obesity is generated by spatiotemporal differences in macrophage subtypes. Diabetes 57: 3239-3246, 2008.

30. Smith LE, Wesolowski E, McLellan A, Kostyk SK, D'Amato R, Sullivan R and D'Amore PA: Oxygen-induced retinopathy in the mouse. Invest Ophthalmol Vis Sci 35: 101-111, 1994.

31. Shen J, Xie B,Dong A,Swaim M,Hackett SF and CampochiaroPA: In vivo immunostaining demonstrates macrophages associate with growing and regressing vessels. Invest Ophthalmol Vis Sci 48: 4335-4341, 2007

32. Mori K, Duh E, Gehlbach P, Ando A, Takahashi K, Pearlman J, Mori K, Yang HS, Zack DJ, Ettyreddy D, et al: Pigment epithelium-derived factor inhibits retinal and choroidal neovascularization. J Cell Physiol 188: 253-263, 2001.

33. Shen J, Yang X, Xie B, Chen Y, Swaim M, Hackett SF and Campochiaro PA: MicroRNAs regulate ocular neovascularization. Mol Ther 16: 1208-1216, 2008.

34. Fujimura S, Takahashi H, Yuda K, Ueta T, Iriyama A, Inoue T, Kaburaki T, Tamaki Y, Matsushima K and Yanagi Y: Angiostatic effect of CXCR3 expressed on choroidal neovascularization. Invest Ophthalmol Vis Sci 53: 1999-2006, 2012.

35. Dong A, Shen J, Zeng M and Campochiaro PA: Vascular celladhesion molecule-1 plays a central role in the proangiogenic effects of oxidative stress. Proc Natl Acad Sci USA 108: 14614-14619, 2011

36. Xin X, Rodrigues M, Umapathi M, Kashiwabuchi F, Ma T, Babapoor-Farrokhran S, Wang S, Hu J, Bhutto I and Welsbie DS: Hypoxic retinal Muller cells promote vascular permeability by HIF-1-dependent up-regulation of angiopoietin-like 4. Proc Nat Acad Sci USA 110: E3425-E3434, 2013.

37. Xie B, Shen J, Dong A, Swaim M, Hackett SF, Wyder L, Worpenberg S, Barbieri S and Campochiaro PA: An Adam15 amplification loop promotes vascular endothelial growth factorinduced ocular neovascularization. FASEB J 22: 2775-2783, 2008

38. Arnold L, Henry A, Poron F, Baba-Amer Y, van Rooijen N, Plonquet A, Gherardi RK and Chazaud B: Inflammatory monocytes recruited after skeletal muscle injury switch into antiinflammatory macrophages to support myogenesis. J Exp Med 204: 1057-1069, 2007

39. Herbert SP and Stainier DY: Molecular control of endothelial cell behaviour during blood vessel morphogenesis. Nat Rev Mol Cell Biol 12: 551-564, 2011
40. Dace DS and Apte RS: Effect of senescence on macrophage polarization and angiogenesis. Rejuvenation Res 11: 177-185, 2008.

41. Kelly J, Ali Khan A, Yin J, Ferguson TA and Apte RS: Senescence regulates macrophage activation and angiogenic fate at sites of tissue injury in mice. J Clin Invest 117: 3421-3426, 2007.

42. Gao X, Wang YS, Li XQ, Hou HY, Su JB, Yao LB and Zhang J: Macrophages promote vasculogenesis of retinal neovascularization in an oxygen-induced retinopathy model in mice. Cell Tissue Res 364: 599-610, 2016.

43. Kelly J, Ali Khan A, Yin J, Ferguson TA and Apte RS: Senescence regulates macrophage activation and angiogenic fate at sites of tissue injury in mice. J Clin Invest 117: 3421-3426, 2007.

44. Sato T, Kusaka S, Hashida N, Saishin Y, Fujikado T and Tano Y: Comprehensive gene-expression profile in murine oxygeninduced retinopathy. Br J Ophthalmol 93: 96-103, 2009.

45. Martinez FO and Gordon S: The M1 and M2 paradigm of macrophage activation: Time for reassessment. F1000Prime Rep 6: 13, 2014.

46. Spiller KL, Anfang RR, Spiller KJ, Ng J, Nakazawa KR, Daulton JW and Vunjak-Novakovic G: The role of macrophage phenotype in vascularization of tissue engineering scaffolds. Biomaterials 35: 4477-4488, 2014

47. Marchetti V, Yanes O, Aguilar E, Wang M, Friedlander D, Moreno S, Storm K, Zhan M, Naccache S, Nemerow G, et al: Differential macrophage polarization promotes tissue remodeling and repair in a model of ischemic retinopathy. Sci Rep 1: 76, 2011.

48. Zhou Y, Yoshida S, Nakao S, Yoshimura T, Kobayashi Y, Nakama T, Kubo Y, Miyawaki K, Yamaguchi M, Ishikawa K, et al: M2 macrophages enhance pathological neovascularization in the mouse model of oxygen-induced retinopathy. Invest Ophthalmol Vis Sci 56: 4767-4777, 2015.

49. Fantin A, Vieira JM, Gestri G, Denti L, Schwarz Q, Prykhozhij S, Peri F, Wilson SW and Ruhrberg C: Tissue macrophages act as cellular chaperones for vascular anastomosis downstream of VEGF-mediated endothelial tip cell induction. Blood 116: 829-840, 2010

50. Caicedo A, Espinosa-Heidmann DG, Piña Y, Hernandez EP and Cousins SW: Blood-derived macrophages infiltrate the retina and activate Muller glial cells under experimental choroidal neovascularization. Exp Eye Res 81: 38-47, 2005.

51. Cao X, Shen D, Patel MM, Tuo J, Johnson TM, Olsen TW and Chan CC: Macrophage polarization in the maculae of age-related macular degeneration: A pilot study. Pathol Int 61: 528-535, 2011

52. Rae F, Woods K, Sasmono T, Campanale N, Taylor D, Ovchinnikov DA, Grimmond SM, Hume DA, Ricardo SD and Little MH: Characterisation and trophic functions of murine embryonic macrophages based upon the use of a Csf1r-EGFP transgene reporter. Dev Biol 308: 232-246, 2007.

53. Troidl C, Möllmann H, Nef H, Masseli F, Voss S, Szardien S, Willmer M, Rolf A, Rixe J, Troidl K, et al: Classically and alternatively activated macrophages contribute to tissue remodelling after myocardial infarction. J Cell Mol Med 13: 3485-3496, 2009.

54. Yan X, Anzai A, Katsumata Y, Matsuhashi T, Ito K, Endo J, Yamamoto T, Takeshima A, Shinmura K, Shen W, et al: Temporal dynamics of cardiac immune cell accumulation following acute myocardial infarction. J Mol Cell Cardiol 62: 24-35, 2013.

55. Ma J, Mehta M, Lam G, Cyr D, Ng TF, Hirose T, Tawansy KA, Taylor AW and Lashkari K: Influence of subretinal fluid in advanced stage retinopathy of prematurity on proangiogenic response and cell proliferation. Mol Vis 20: 881-893, 2014.

56. Outtz HH, Tattersall IW, Kofler NM, Steinbach N and Kitajewski J: Notch1 controls macrophage recruitment and Notch signaling is activated at sites of endothelial cell anastomosis during retinal angiogenesis in mice. Blood 118: 3436-3439, 2011.

57. Sethi G, Sung B and Aggarwal BB: TNF: A master switch for inflammation to cancer. Front Biosci 13: 5094-5107, 2008.

58. Bartneck M, Heffels KH, Pan Y, Bovi M, Zwadlo-Klarwasser G and Groll J: Inducing healing-like human primary macrophage phenotypes by 3D hydrogel coated nanofibres. Biomaterials 33 : 4136-4146, 2012.

59. Fuentes-Duculan J, Suárez-Fariñas M, Zaba LC, Nograles KE, Pierson KC, Mitsui H, Pensabene CA, Kzhyshkowska J, Krueger JG and Lowes MA: A subpopulation of CD163-positive macrophages is classically activated in psoriasis. J Invest Dermatol 130: 2412-2422, 2010. 